\title{
Mapeamento e diagnóstico de nascentes e do curso d'agua do riacho Corrente dos Matões, Bom Jesus, Piauí
}

\author{
Mapping and diagnosis of springs and the water course of the river Corrente dos Matões, Bom \\ Jesus, Piauí \\ Mapeo y diagnóstico de muelles y curso de aguas del río corriente Matões, Bom Jesus, Piauí
}

Recebido: 15/11/2021 | Revisado: 22/11/2021 | Aceito: 23/11/2021 | Publicado: 05/12/2021

Kamylla Gonçalves Oliveira Assis

ORCID: https://orcid.org/0000-0003-1452-7762 Universidade Federal do Piaú, Brasil

E-mail: kamylla@ufpi.edu.br

João Carlos Medeiros

ORCID: https://orcid.org/0000-0001-7745-7015

Universidade Federal do Sul da Bahia, Brasil

E-mail: joao.medeiros@ufsb.edu.br

Yuri Jacques Agra Bezerra da Silva

ORCID: https://orcid.org/0000-0001-6865-7146 Universidade Federal do Piauí, Brasil

E-mail: yurijacques@ufpi.edu.br

Marcos Paulo Rodrigues Teixeira

ORCID: https://orcid.org/0000-0001-8961-3599 Universidade Federal do Piaú, Brasil

E-mail: marcosteixeira@ufpi.edu.br

Gustavo Saraiva da Silva

ORCID: https://orcid.org/0000-0001-6704-0486 Universidade Federal do Piauí, Brasil

E-mail: gsaraiva123@gmail.com

Cássia Ribeiro Macedo

ORCID: https://orcid.org/0000-0003-1427-8225

Universidade Federal de Viçosa, Brasil

E-mail: cassia.macedo@ufv.br

\begin{abstract}
Resumo
O objetivo deste estudo é a avaliação ambiental macroscópica das nascentes e suas áreas de preservação permanente e do leito localizados na bacia do riacho Corrente do Matões. O estudo foi conduzido na bacia do riacho Corrente dos Matões, onde foram realizadas viagens de campo a fim de avaliar a vegetação, impactos ambientais, aspectos geológicos, caracterização da área de preservação permanente associada à nascente, acesso direto de animais, presença de resíduos domésticos nas nascente e entorno, construções, captações de água, múltiplos usos, proximidade de atividades impactantes, além de outros aspectos que foram anotados e registrados com uma máquina fotográfica e um GPS. Também foram realizadas coletas de amostras de água para avaliar a concentração de alguns elementos químicos. Diante da análise deste estudo registrou-se que o Riacho Corrente dos Matões possui cinco nascentes, sendo alimentado apenas por três. O estudo também revelou que de acordo com o uso do solo os impactos são diferentes na bacia do riacho Corrente dos Matões e que mesmo sendo um rio situado na zona rural, sofre pressões com o avanço da urbanização.
\end{abstract}

Palavras-chave: Avaliação ambiental; Conservação do solo e da água; Geoprocessamento.

\begin{abstract}
The aim of this study is the macroscopic environmental assessment of the springs and their permanent preservation areas and the bed located in the basin of the Corrente do Matões stream. The study was conducted in the basin of the Corrente dos Matões stream, where field trips were carried out in order to assess the vegetation, environmental impacts, geological aspects, characterization of the permanent preservation area associated with the spring, direct access to animals, presence of household waste in the springs and surroundings, constructions, water collection, multiple uses, proximity to impacting activities, in addition to other aspects that were noted and recorded with a camera and a GPS. Collections of water samples were also carried out to assess the concentration of some chemical elements. In view of the analysis of this study, it was registered that the Riacho Corrente dos Matões has five springs, being fed only by three. The study also revealed that, depending on the use of the land, the impacts are different in the basin of the Corrente dos Matões stream and that, even though it is a river located in the rural area, it suffers pressure with the advance of urbanization.
\end{abstract}

Keywords: Environmental assessment; Soil and water conservation; Geoprocessing. 


\section{Resumen}

El objetivo de este estudio es la evaluación ambiental macroscópica de los manantiales y sus áreas de conservación permanente y el lecho ubicado en la cuenca del arroyo Corrente do Matões. El estudio se realizó en la cuenca del arroyo Corrente dos Matões, donde se realizaron viajes de campo con el fin de evaluar la vegetación, impactos ambientales, aspectos geológicos, caracterización del área de preservación permanente asociada al manantial, acceso directo a los animales, presencia de residuos domiciliarios en los manantiales y alrededores, construcciones, captación de agua, usos múltiples, proximidad a actividades impactantes, además de otros aspectos que se anotaron y registraron con cámara y GPS. También se realizaron recolecciones de muestras de agua para evaluar la concentración de algunos elementos químicos. A la vista del análisis de este estudio, se registró que el Riacho Corrente dos Matões tiene cinco manantiales, siendo alimentado solo por tres. El estudio también reveló que, dependiendo del uso del suelo, los impactos son diferentes en la cuenca del arroyo Corrente dos Matões y que, aunque es un río ubicado en la zona rural, sufre presiones con el avance de la urbanización.

Palabras clave: Evaluación ambiental; Conservación de suelos y aguas; Geoprocesamiento.

\section{Introdução}

As margens dos rios desempenham importantes funções ambientais. De acordo com Pelegrini (2021), as áreas de preservação permanentes (APP's) são essenciais para preservação da paisagem, estabilidade dos ciclos hidrológicos (Arana et al. 2018). Essas áreas encontram-se nas margens dos corpos hídricos em faixas de largura variável nas encostas íngremes, topos de morro, além de outros locais especificados pelo código florestal. A qualidade dos recursos hídricos é impactada por diversas atividades antrópicas a exemplo da remoção da cobertura vegetal, queimadas e atividades de mineração (Daryanto et al., 2020, Zhou et al., 2021).

Práticas agrícolas inadequadas de uso do solo, revolvimento excessivo e impermeabilização, promovem a sua degradação e consequentemente o transporte de partículas orgânicas e inorgânicas por meio de processos erosivos (Li et. al. 2021). O material transportado é depositado no leito dos cursos d'água e dos lagos, o que pode promover assoreamento e redução do volume de água (de Faria, et al., 2019). Diante desse cenário, o Ministério do Meio Ambiente (MMA) (CONAMA, 2016) afirma que é de suma importância preservar a vegetação no entorno das nascentes, com a função de proteger a superfície do solo e manter características propícias à infiltração da água no solo. Quando não apresenta vegetação preservada no seu entorno, a nascente está mais susceptível a processos erosivos prejudicando a capacidade do solo com a diminuição na fertilidade e na produtividade das colheitas e aumentando o risco de desastres naturais (Ferreira et al., 2018, Panagos et al., 2015). Para mitigar processos erosivos e, consequentemente, o assoreamento e degradação dos recursos hídricos nascentes, uma das opções mais importantes é a proteção das nascentes (Montanarella et al., 2016).

As nascentes estudadas têm uma grande importância e múltiplos usos, como: consumo humano, produção de alimentos, geração de renda, possibilitando a fixação do homem no meio rural (Dennedy-Frank et al., 2016; Xiao et al., 2017). A despeito destes fatores, há um enorme contraste com a situação encontrada nas comunidades instaladas no entorno das nascentes e dos rios, que por falta de conhecimento de seus moradores, desmatam a área de preservação permanente, potencializando processos erosivos e o comprometimento dos recursos hídricos, que têm como consequência, a redução da vazão, contaminação da água e até a "morte" de muitas nascentes (Jian et. al. 2018). A região do Alto Médio Gurguéia, Sudoeste do Estado do Piauí, onde o município de Bom Jesus está localizado, apresenta um grande potencial agrícola, sendo considerado a última fronteira agrícola do país. Apesar do clima quente e seco na maior parte do ano, a região apresenta boa disponibilidade de água subterrânea, com diversos poços jorrantes, que têm possibilitado o desenvolvimento da agricultura irrigada (Bastos et al., 2008).

A urbanização no município de Bom Jesus - PI provocou mudanças drásticas na natureza, desencadeando diversos problemas ambientais, como poluição, desmatamento, redução da biodiversidade e descarte inadequado de resíduos sólidos. O aumento populacional causou uma maior produção de lixo, muitas vezes sem ter o destino correto. Portanto, diante desse cenário de diferentes problemas ambientais, é urgente a necessidade de elaboração e aplicação de políticas ambientais eficazes, além da 
conscientização da população. Entre as medidas a serem tomadas, estão a redução da produção do lixo, o saneamento ambiental, o planejamento urbano, a educação ambiental, a redução da emissão de gases poluentes, a conservação da cobertura do solo e diminuição do desperdício de água. Assim, o objetivo deste estudo é a avaliação ambiental macroscópica das nascentes e suas áreas de preservação permanente e do leito localizados na bacia do riacho Corrente do Matões.

\section{Metodologia}

\section{1 Área de estudo}

O estudo foi conduzido na bacia do riacho Corrente dos Matões. Essa área de captação está localizada no município de Bom Jesus, sudoeste do Piauí, localizada aproximadamente entre latitude -09 14'07, 98000” e longitude - 44 27’29, 70000”. A bacia hidrográfica cobre aproximadamente $964,5 \mathrm{Km}^{2}$, dentro de um perímetro de 168,7 Km de extensão e com 63,5 Km de comprimento do rio principal (Figura 1). A sub-bacia tem sua jusante caracterizada com o nome de um pequeno povoado, chamado Barra Verde, para o qual auxilia na alimentação do rio no Rio Gurguéia.

Figura 1. Localização e classes de solo do riacho Corrente dos Matões.

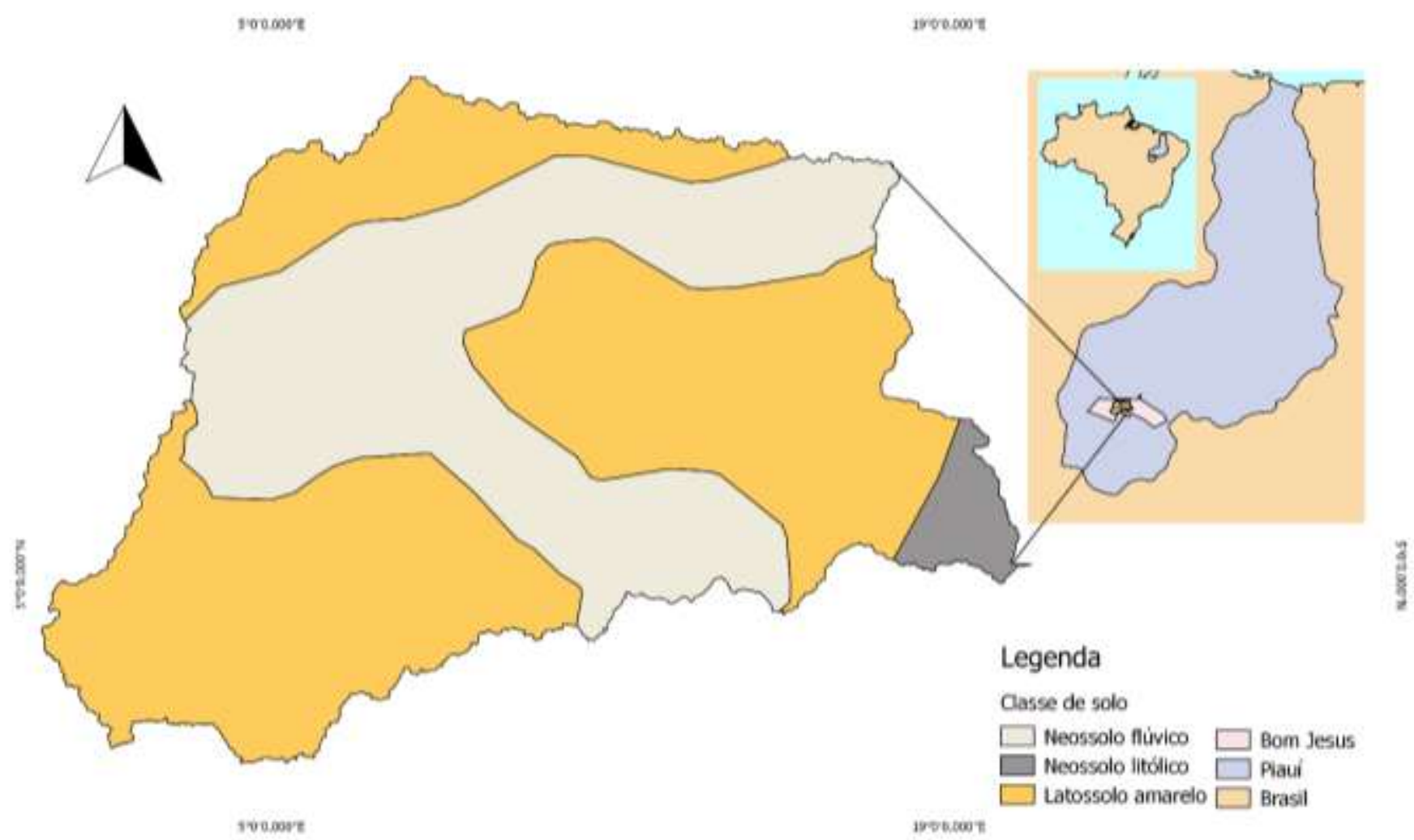

Fonte: Autores (2021).

$\mathrm{Na}$ área da bacia observa-se flora bem preservada com característica de mata típica do cerrado, com presença de espécies semi-decídua, decídua e epífitas, e de mata típica da caatinga, com presença de árvores e arbustos baixos com galhos retorcidos, ervas rasteiras e cacto. É possível verificar também a presença da área de preservação permanente que margeia o curso do rio. Dessa forma, existe um microclima bem peculiar. Na bacia, a vegetação do cerrado mais densa domina a paisagem e abrange $33 \%$ do total; já a área de atividade com agricultura e pecuária cobre cerca de $27 \%$ da bacia. A altitude varia de $261 \mathrm{~m}$ a $660 \mathrm{~m}$. O clima é quente e semiárido, com precipitação pluviométrica média anual de $900 \mathrm{~mm}$ e é definida no Regime Equatorial Continental no qual contém faixas de precipitação em torno de 800 a $1200 \mathrm{~mm}$ e apresenta temperaturas mínimas de $18^{\circ} \mathrm{C}$ e máximas de $36^{\circ} \mathrm{C}$. O período mais úmido corresponde aos meses de novembro a fevereiro (Jacomine, 1986). 
A partir da base de dados do IBGE referente ao levantamento das classes de solos do Brasil, foi determinada as classes de solos que compreendem a área de estudo (Figura 1) Latossolo Amarelo, Neossolo Litólico e Neossolo Flúvico. Os Latossolos Amarelos são predominantes na região, ocupando 60,4\% de sua área. Esse tipo de solo apresenta, de forma geral, boas condições físicas, sendo intensivamente utilizados para culturas de mandioca e pastagens. Entretanto, as áreas com maior susceptibilidade a processos erosivos se concentram ao longo dos Neossolos Litólicos (37,05\% da área da Bacia). A textura dominante do solo da bacia é franco-arenosa, porém podem ser encontrados solos com textura franco e franco argilosa. O acidente morfológico predominante na mesma, é a ampla superfície tabular reelaborada, plana ou levemente ondulada, margeada por escarpas que podem atingir $600 \mathrm{~m}$ (Jacomine et al., 1986). Os LATOSSOLOS são solos cujas características encontravam-se fortemente relacionadas à intemperização e lixiviação intensas e responsáveis pelas baixas atividade das argilas. Os LATOSSOLOS AMARELOS encontram-se espalhados em muitas áreas do Brasil, onde normalmente desenvolvem-se a partir de sedimentos do Grupo Barreiras (Pliopleistoceno) e Formação Alter do Chão (Cretáceo). Os NEOSSOLOS formam-se em materiais praticamente inertes, sem argilas e extremamente resistentes ao intemperismo ou estão pouco e recentemente expostos aos processos pedogenéticos. Os NEOSSOLOS LITÓLICO distribuem por todo o Brasil, com predomínio em declives fortes de áreas com relevo movimentado. Os FLÚVICOS, ao contrário situam-se em relevos aplainados e têm espessura significativa para o desenvolvimento do sistema radicular dos cultivos, no entanto, podem estar sujeitos a frequentes inundações.

\subsection{Procedimentos adotados para realização do diagnóstico Expedições às Nascentes}

As expedições às nascentes (viagens de campo) foram guiadas por um morador da região e precedidas de entrevista com moradores, preparação de mapas, delimitação da área estudada, definição de roteiros e locais a serem visitados. Ao chegar às áreas, procurou-se entrevistar lideranças locais, moradores e agricultores para melhor definição das nascentes a serem visitadas. Durante os percursos até as nascentes, aspectos como vegetação, impactos ambientais, aspectos geológicos (litologias, presença de fraturas e falhas, etc.), caracterização da área de preservação permanente associada à nascente a ser estudada, acesso direto de animais, presença de resíduos na nascente e entorno, construções, captações de água, múltiplos usos, proximidade de atividades impactantes, entre outros aspectos eram observados, anotados e registrados com uma máquina fotográfica e um GPS.

\subsection{Geoprocessamento}

A localização geográfica das nascentes foi obtida por meio do uso de GPS, formatado com o datum SIRGAS 2000 e sistema de coordenada plana UTM. Estes pontos foram processados com o uso do software ArcGis 10.2. Com base no relevo e na rede hidrográfica, foram geradas as bacias hidrográficas da área em estudo, corrigidas, quando necessário, manualmente.

Na geração do Modelo Digital de Elevação (MDE) foram utilizadas imagens do satélite LANDSAT 8, disponibilizadas no site USGS. Esses MDE vistos nas pranchas de localização das nascentes estudadas mostram nas cotas inferiores a $200 \mathrm{~m}$ tons azulados; cotas entre 200 e 500 metros apresentam tonalidades esverdeadas e amareladas; e cotas superiores a 500 metros mostram tons avermelhados.

Na classificação do uso do solo foram utilizadas imagens do satélite LANDSAT 8 disponibilizadas no site da USGS, onde foi possível classificar a bacia hidrográfica do riacho do Corrente dos Matões em Mata Ciliar/Cerrado, Solo exposto/agricultura, Campo Cerrado/Campo sujo e Cerrado Stricto sensu de acordo com as classes determinada pela EMBRAPA.

\subsection{Análise e Avaliação Ambiental das Nascentes}

A análise e avaliação ambiental das nascentes tiveram como fundamentação conceitual a Resolução CONAMA 001, de 23 de janeiro de 1986 (CONAMA, 1986), que define os 25 critérios básicos e as diretrizes gerais para uso e implementação da Avaliação de Impacto Ambiental contendo o diagnóstico e análise ambiental da área de influência das nascentes estudadas com a completa descrição e análise dos recursos ambientais e suas interações, tal como existem, de modo a caracterizar a situação 
ambiental da área, em seus aspectos dos meios físico, biológico e socioeconômico. Em seu artigo sexto, essa Resolução explicita que o estudo de impacto ambiental desenvolverá, no mínimo, as seguintes atividades:

[...] II - Análise dos impactos ambientais do projeto e de suas alternativas, através de identificação, previsão da magnitude e interpretação da importância dos prováveis impactos relevantes, discriminando: os impactos positivos e negativos (benéficos e adversos), diretos e indiretos, imediatos e a médio e longo prazos, temporários e permanentes; seu grau de reversibilidade; suas propriedades cumulativas e sinérgicas; a distribuição dos ônus e benefícios sociais. III - Definição das medidas mitigadoras dos impactos negativos, entre elas os equipamentos de controle e sistemas de tratamento de despejos, avaliando a eficiência de cada uma delas. IV - Elaboração do programa de acompanhamento e monitoramento dos impactos positivos e negativos, indicando os fatores e parâmetros a serem considerados. (CONAMA, 1986, p.1)

Foi elaborado um modelo para auxiliar os diagnósticos sobre o estado de conservação de nascentes e programas de recuperação condizente com a realidade local. O modelo foi empregado durante a fase de condução das visitas e de monitoramento, o que permite acompanhar mudanças desejáveis e indesejáveis na área. Nesse modelo considera-se aspectos do solo, água, vegetação onde são estabelecidos da seguinte forma:

- Formas de uso do solo - Será realizada a avaliação do uso atual do solo no entorno da nascente e nas margens do rio, observando os possíveis conflitos de uso nas áreas de preservação permanente e suas consequências. O critério conta como encontra-se a área, se possui cobertura nativa (floresta, cerrado ou campo) ou se está sendo desenvolvida atividades agropecuárias.

- Estado de conservação da vegetação - Será avaliado o estado de conservação da vegetação. Nesse passo, procura-se observar a extensão da área coberta por vegetação no entorno da nascente. Durante a avaliação, examina-se toda a área do entorno da nascente e a presença de APP's.

- Estado de conservação do solo - Será avaliada a existência de erosão ou processo de degradação acentuado observando se o solo no entorno de uma nascente apresenta sulcos, voçorocas e camadas de serrapilheira onde podem ser capazes de reter e absorver o escoamento superficial em toda sua extensão.

- Presença e aparência da água - Quando observada a presença de água, procura-se avaliar os critérios de coloração, turbidez e a existência de material em suspensão na água. Observou-se, também, fatores como presença de lixo, odores, vestígio de gado e fauna aquática. Esta metodologia foi aplicada em todas as nascentes do riacho Corrente dos Matões e do leito do rio Gurgueia, sendo que a análise e interpretação destes resultados mostram o quão elas estão preservadas ou não.

\subsection{Análise da qualidade da água}

Foram realizadas coletas de amostras de água do riacho Corrente dos Matões próximo as nascentes e próximo ao exutório em datas representativas dos períodos de menor e maior vazão. As amostras de água foram encaminhadas ao laboratório da Universidade Federal do Piauí, onde foram realizadas análises de: pH, cálcio, magnésio, cádmio, chumbo, sódio, potássio, alcalinidade, dureza e condutividade elétrica.

\section{Resultados e Discussão}

De acordo com as imagens de satélite, o Riacho Corrente dos Matões possui cinco nascentes que o alimenta, localizadas no povoado Corrente dos Matões, mas nas visitas ao local constatamos a presença de três, nomeadas como Rosa Dias, Tamboril e Taboca. O riacho Corrente dos Matões é o principal afluente do rio Gurguéia, onde alimenta o rio Parnaíba, maior rio genuinamente nordestino, sendo navegável em toda sua extensão. 
Na visita a nascente do Tamboril, não foram encontrados nenhum sinal de água (Figura 2). De acordo com os moradores, essa nascente encontra-se seca ao longo dos últimos anos. Na nascente Taboca foi possível observar a presença de água no local. Esta nascente está bem conservada e com ausência de animais domésticos, lixos e odor na água. Uma das nascentes fica localizada na fazenda Rosa Dias, por isso foi denominada de nascente Rosa Dias. De acordo com moradores, na época chuvosa ocorre a formação de uma lagoa. Como o local foi visitado na época seca, não foi possível registrar a lagoa cheia.

Figura 2. A) Nascente Rosa dias; B) Lagoa Rosa Dias seca; C e D) Local da nascente Tamboril de acordo com moradores; E e F) Nascente Taboca.

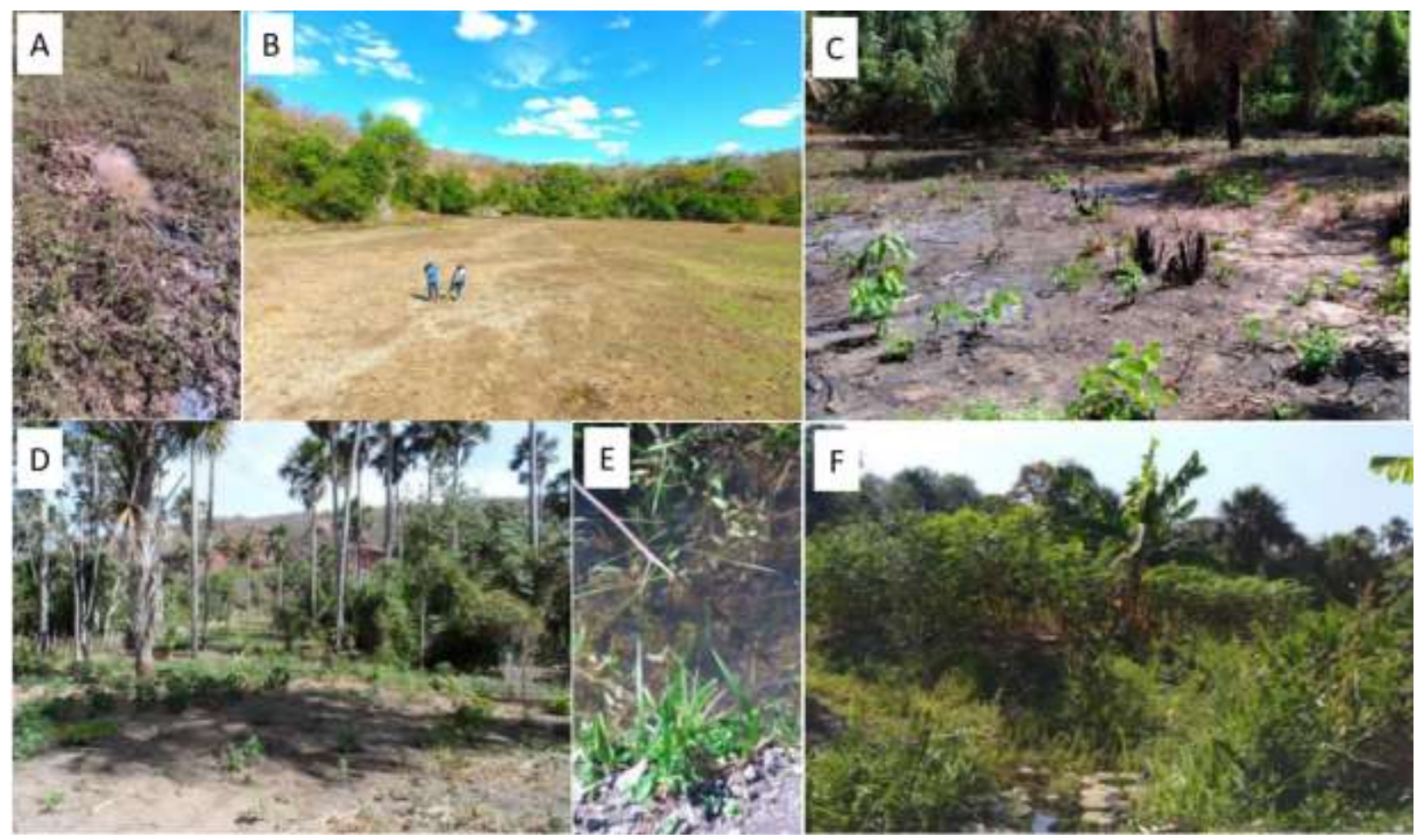

Fonte: Autores (2021).

O riacho Corrente dos Matões é utilizado como fonte de água para consumo humano, animal, fins recreativos, para produção de alimentos, criação de animais e irrigação de pequenas lavouras. É um riacho perene, suas águas deságuam no rio Gurguéia. Seu curso d'água se localiza em uma região tipicamente rural e de transição entre a caatinga e o cerrado. Na visita ao riacho Corrente dos Matões foi possível observar que quanto mais próximos as nascentes, um maior grau de conservação das áreas de preservação permanentes, quanto mais próximo ao exutório maior grau de impactos antrópicos.

No local das nascentes a mata ciliar é bem conservada e nas comunidades mais próximas as nascentes, não foram encontrados grandes acúmulos de lixos e presença de animais, mas há construções residências próximas ao rio. Em alguns trechos do riacho observa-se a presença de humanos, animais e lixos. Em algumas propriedades foram construídos tanques de peixes, sistema de irrigação das lavouras e poços artesianos. O riacho é utilizado para lavagens de roupas e de automóveis, onde foram encontrados uma grande presença de lixo nesses locais. Em todo o trecho do riacho Corrente dos Matões é possível encontrar áreas de lazer para os habitantes, mas no exutório, localizado na comunidade Barra Verde, é onde há uma melhor estrutura para receber visitantes (Figura 3). O riacho Corrente dos Matões é o principal afluente do rio Gurguéia, a união dos dois rios ocorre há aproximadamente $3 \mathrm{~km}$ do exutório da bacia. No local há presença de lixo, a água é mais turva do que nas nascentes e observase uma maior quantidade de sedimentos na água. A grande preocupação é o assoreamento do riacho no futuro. 
Figura 3. A) Imagem panorâmica do leito do rio; B) Imagem panorâmica da comunidade Corrente dos Matões; C) Passarela feita sobre o riacho por moradores; D) Plantações e criações de animais próximo ao leito do riacho; E) Lixo próximo ao leito do rio; F) Lavagem de roupa as margens do riacho; G) Poço nas margens do riacho; H) Tanque de peixe nas margens do riacho; I) Local de lazer dos moradores e visitantes.

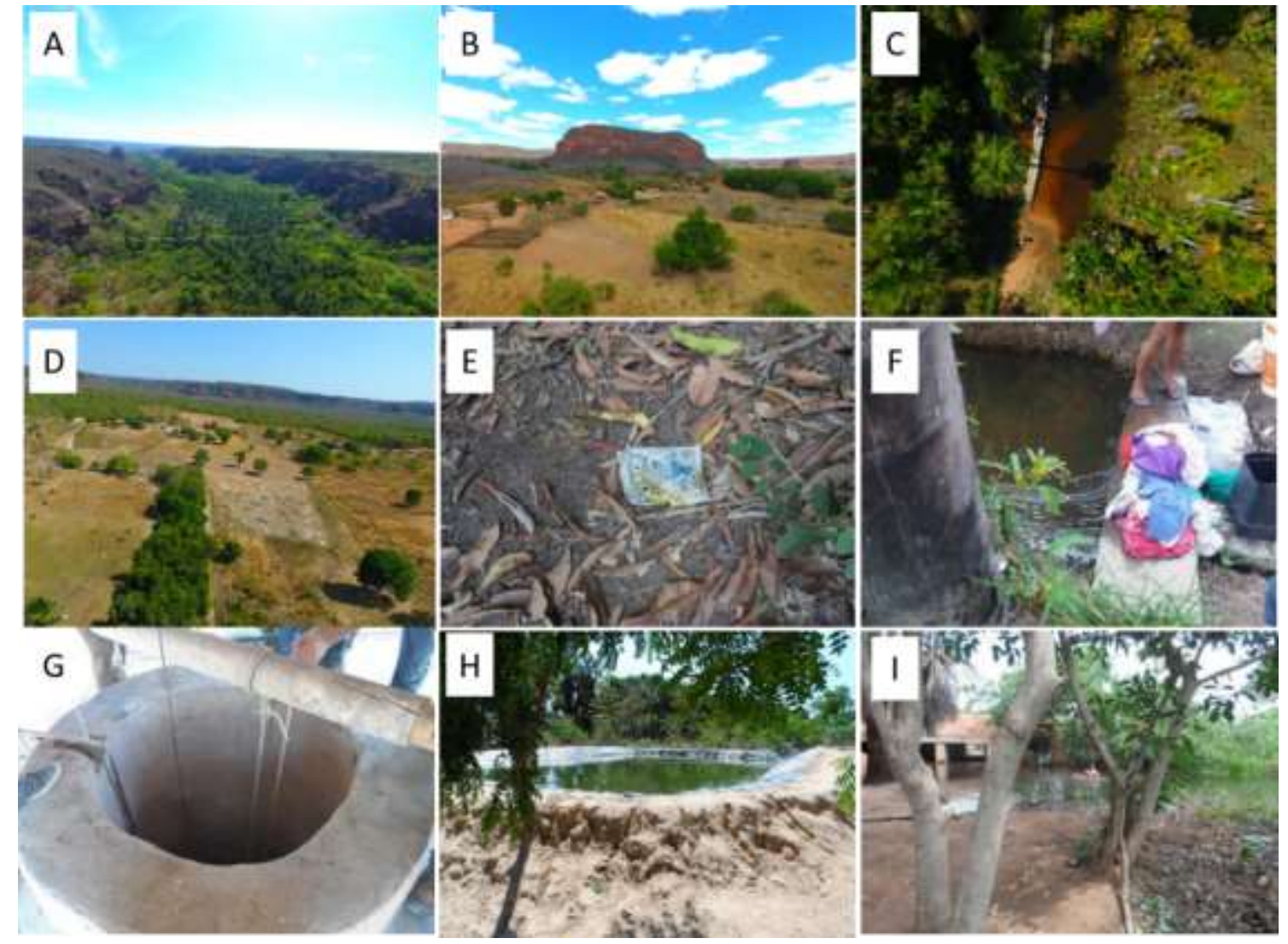

Fonte: Autores (2021).

As margens do riacho Corrente dos Matões por ser muito fértil é muito utilizada para lavouras. Podendo ser encontradas culturas como: mandioca, feijão, milho, cajueiros e mangueiras. Na comunidade Barra Verde, próximo à foz do Riacho Corrente dos Matões no Rio Gurgueia, observa-se a presença de sulcos já bem acentuados, ocasionadas pela forte enxurrada nos períodos chuvosos e a falta de cobertura no solo. Esse solo perdido é todo carregado para o riacho, provocando o assoreamento.

Esta bacia hidrográfica está sujeita a múltiplas pressões humanas, tais como desmatamento da APP's para o desenvolvimento de atividade como agricultura, pecuária e lazer, muitas vezes realizadas de forma inadequadas agravam a erosão do solo, especialmente quando as condições climáticas são bastante desfavoráveis. Segundo Warburton et al. (2012), o efeito da mudança da cobertura do solo em uma bacia hidrográfica depende do grau de modificação da cobertura natural da terra por influência humana, intensidade, localização e tipo de mudança dentro de uma bacia, refletindo diretamente a influência da atividade humana na qualidade da água do rio e na ecologia da água (Gu et al., 2019). Com isso, uma pequena bacia hidrográfica $\left(<1 \mathrm{~km}^{2}\right)$ responde mais fortemente à mudança do uso da terra do que uma grande bacia hidrográfica $\left(>100 \mathrm{~km}{ }^{2}\right)$ que tem muitos processos complexos interagindo entre si (Costa et al., 2003).

A partir da classificação das imagens do sensor OLI - Landsat - 8 foram gerados os mapas de uso atual do solo (Figura 4). Após a elaboração do mapa temático detalhou-se os dados da área de cobertura de cada parâmetro e suas respectivas porcentagens. O Cerrado Sensu Strict corresponde a uma área de $312,7 \mathrm{~km}^{2}$, sendo a maior porcentagem encontrada na subbacia. Essa área caracteriza-se pela presença de árvores baixas, inclinadas e tortuosas, de tronco fino, com ramificações irregulares e retorcidas, geralmente com evidências de queimadas, e presença de grande quantidade de gramíneas no sub-bosque. 
Figura 4. Mapa de classificação do solo da bacia do riacho Corrente dos Matões.

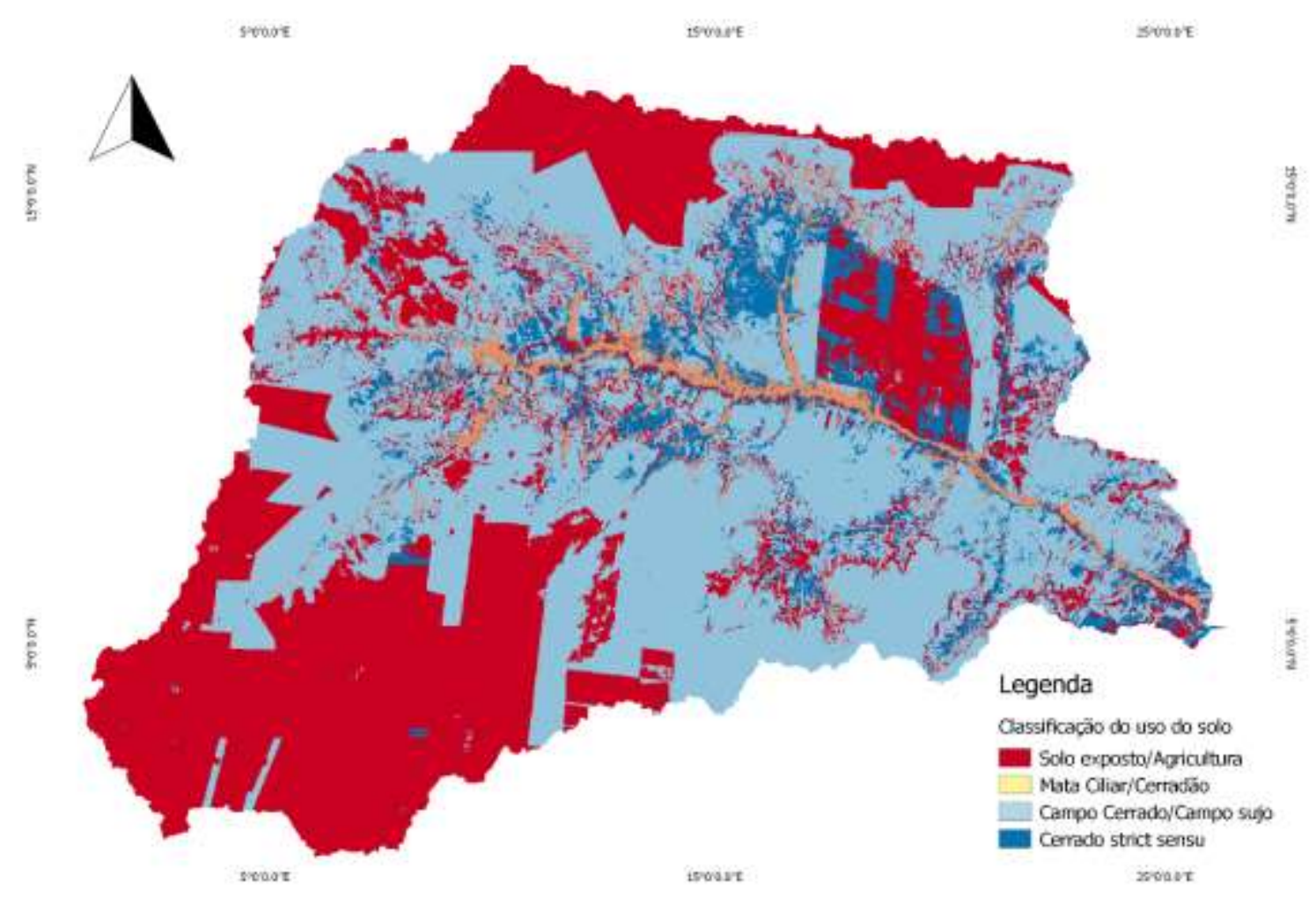

Fonte: Autores (2021).

$\mathrm{Na}$ área da sub-bacia observa-se que 270,1098 km² destina-se a área de Campo cerrado/Campo sujo, formado de vegetação com fisionomia herbácea e arbustiva com arbustos e subarbustos espaçados entre si, geralmente estão sobre solos mais rasos que podem apresentar pequenos trechos de rochas ou solos mais profundos, mas pouco férteis.

Na Figura 4 também é possível observar que 259,9746 km² estão ocupados com a agricultura ou são áreas de solo exposto. Isto é preocupante pois a substituição da vegetação nativa geralmente resulta no aumento do transporte de nutrientes para os ecossistemas aquáticos, reduzindo a qualidade da água destes ambientes.

E a menor porcentagem encontrada, destina-se a área de 121,77 km², com características de Mata Ciliar/ Cerradão, possuem uma grande importância ambiental, pois, exercem a proteção do solo contra processos erosivos com as chuvas em locais desprovidos de mata ciliar.

A urbanização pode ter causado aumento nas quantidades de elementos presente nas amostras de água do riacho Corrente dos Matões (Figura 5), quando comparamos as médias dos valores próximos a nascentes com os valores do exutório. É possível observar um grande aumento na quantidade de Potássio. Esses valores podem ser oriundos das atividades agrícolas nas margens do riacho, o que corrobora Luo, Zengliang et al. (2020) que observaram que a expansão urbana acompanhada pelo crescimento populacional e pelo aumento da atividade humana é um fator importante que impulsiona o impacto nas águas dos rios. 
Figura 5. Médias da análise de amostras de água da nascente e exutório do riacho Corrente dos Matões.

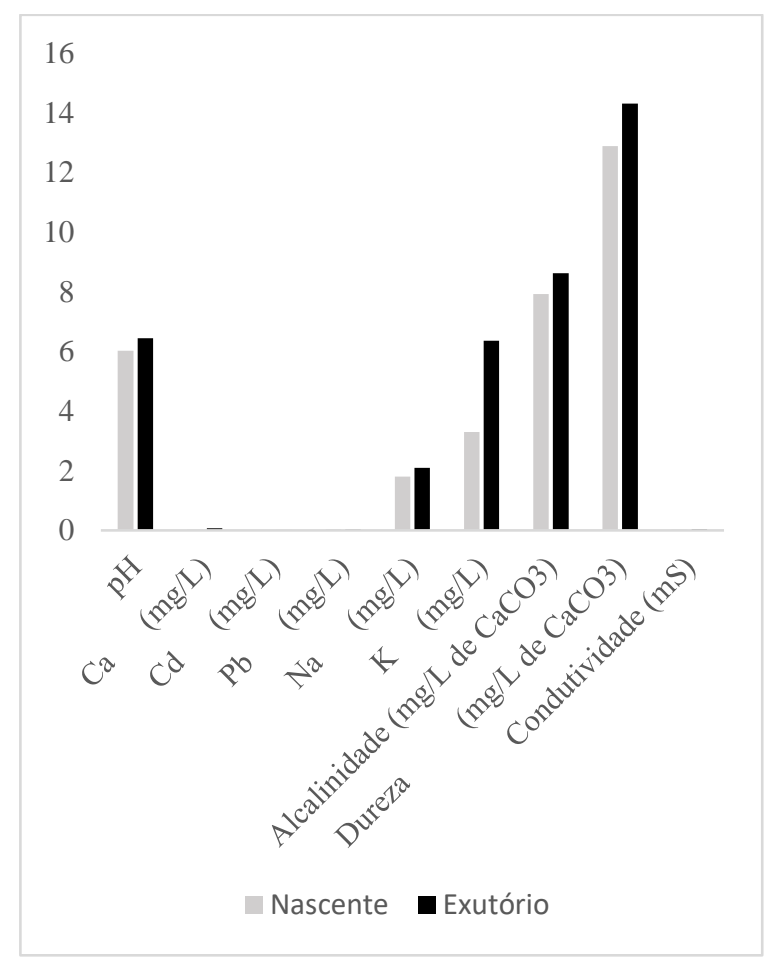

Fonte: Autores (2021).

\section{Conclusão}

Com o estudo foi possível identificar que as nascentes do riacho Corrente dos Matões estão conservadas, porém existe a necessidade de avaliar melhor os efeitos da urbanização. Em todo o trecho do rio foi possível observar sinais de impactos no riacho, podendo no futuro afetar a qualidade da água. Os fatores por trás das mudanças no uso da terra devem ser considerados como prioridade para uma gestão adequada dos recursos hídricos da região.

É necessário estudos mais aprofundados sobre a contribuição de sedimentos e a qualidade da água no riacho Corrente dos Matões afim de avaliar o impacto do uso do solo na Bacia do riacho Corrente dos Matões.

\section{Referências}

Arana, A. R. A. et al. Gestão das águas e planejamento ambiental: áreas de preservação permanente no manancial do alto curso do rio Santo Anastácio-SP. Revista Brasileira de Geografia Física, 11(2), 674-686.

Bastos, E. A.; et. al. Evapotranspiração e coeficiente de cultivo do feijão-caupi no Vale do Gurguéia, Piauí. Irriga, 13(2), 182-190.

CONAMA, R. (1986). No 001, de 23 de janeiro de 1986. Publicado no DOU de, 17(02).

Costa, M. H., Botta, A., \& Cardille, J. A. (2003). Effects of large-scale changes in land cover on the discharge of the Tocantins River, Southeastern Amazonia. Journal of hydrology, 283(1-4), 206-217.

Daryanto, S., Wang, L., \& Jacinthe, P. A. (2020). No-till is challenged: Complementary management is crucial to improve its environmental benefits under a changing climate. Geography and Sustainability, 1(3), 229-232.

Dennedy-Frank, P. J., Muenich, R. L., Chaubey, I., \& Ziv, G. (2016). Comparing two tools for ecosystem service assessments regarding water resources decisions. Journal of Environmental Management, 177, 331-340.

De Quioto, Protocolo. Ministério do meio Ambiente. http://www. mma. gov. br/clima/convencao-das-nacoes-unidas/protocolo-de-quioto>

Ferreira, C. S., Pereira, P., \& Kalantari, Z. (2018). Human impacts on soil.

de Faria Ferreira, N. C., de Mello Duarte, J. R., de Oliveira, L. A. B., da Silva, E. C., \& de Carvalho, I. A. (2019). O Papel Das Matas Ciliares Na Conservação Do Solo E Água. Biodiversidade, 18(3). 
Research, Society and Development, v. 10, n. 16, e37101623350, 2021

Jacomine, P. K. T., Cavalcanti, A. C., Ribeiro, M. R., Montenegro, J. O., Burgos, N., de Mélo Filho, H. F. R., \& Formiga, R. A. (1976). Levantamento exploratório-reconhecimento de solos da margem esquerda do Rio São Francisco Estado da Bahia. Embrapa Solos-Séries anteriores (INFOTECA-E).

Gu, Q., Hu, H., Ma, L., Sheng, L., Yang, S., Zhang, X., ... \& Chen, L. (2019). Characterizing the spatial variations of the relationship between land use and surface water quality using self-organizing map approach. Ecological Indicators, 102, 633-643.

Jian, S. U. N., Yu, L. I. U., Tiancai, Z. H. O. U., Guohua, L. I. U., \& Jingsheng, W. A. N. G. (2018). Soil conservation service on the Tibetan Plateau, 19842013. Earth and Environmental Science Transactions of the Royal Society of Edinburgh, 109(3-4), 445-451.

Li, M., Liang, D., Xia, J., Song, J., Cheng, D., Wu, J., ... \& Li, Q. (2021). Evaluation of water conservation function of Danjiang River Basin in Qinling Mountains, China based on InVEST model. Journal of Environmental Management, 286, 112212.

Montanarella, L., Pennock, D. J., McKenzie, N., Badraoui, M., Chude, V., Baptista, I., ... \& Vargas, R. (2016). World's soils are under threat. Soil, 2(1), 79-82.

Luo, Z., Shao, Q., Zuo, Q., \& Cui, Y. (2020). Impact of land use and urbanization on river water quality and ecology in a dam dominated basin. Journal of Hydrology, 584, 124655.

Panagos, P., Borrelli, P., Poesen, J., Ballabio, C., Lugato, E., Meusburger, K., ... \& Alewell, C. (2015). The new assessment of soil loss by water erosion in Europe. Environmental science \& policy, 54, 438-447.

Pelegrini, M. dos S. Áreas de preservação permanente urbanas e análise de Inundações no município de são carlos-aplicação do código florestal brasileiro no córrego do Monjolinho. Brazilian Journal of Animal and Environmental Research, 4(3), 3003-3017.

Xiao, Q., Hu, D., \& Xiao, Y. (2017). Assessing changes in soil conservation ecosystem services and causal factors in the Three Gorges Reservoir region of China. Journal of Cleaner Production, 163, S172-S180.

Zhou, N., Hu, X., Byskov, I., Næss, J. S., Wu, Q., Zhao, W., \& Cherubini, F. (2021). Overview of recent land cover changes, forest harvest areas, and soil erosion trends in Nordic countries. Geography and Sustainability, 2(3), 163-174.

Warburton, M. L., Schulze, R. E., \& Jewitt, G. P. (2012). Hydrological impacts of land use change in three diverse South African catchments. Journal of Hydrology, 414, 118-135. 